Revista de Derecho

\title{
Derecho y arte. La epistemología del oprimido en la enseñanza del derecho desde un diálogo con el cine
}

Law and Art. The Epistemology

of the Oppressed in the Teaching of Law

from a Dialogue with the Cinema

\section{Paúl Córdova Vinueza}

Docente en Universidad Central del Ecuador y Universidad Técnica del Norte, Ecuador hpaulcordova@yahoo.es

ORCID: https://orcid.org/0000-0002-3125-5861

DOI: https://doi.org/10.32719/26312484.2020.33.4

Fecha de recepción: 2 de abril de 2018

Fecha de aceptación: 18 de enero de 2019

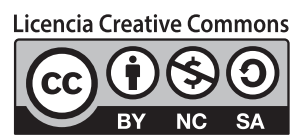




\section{RESUMEN}

El objetivo del artículo es hacer una reinvención de las dimensiones epistemológicas que aparecen en la enseñanza y en el aprendizaje del derecho mediante el intercambio de razones críticas que se observarían con la ayuda de materiales como historias cinematográficas de casos relacionados con la aplicación del derecho.

Para ello, la discusión surgió de hacer una aproximación a dos tipos de epistemología: i) la de la dominación y ii) la del oprimido, con el fin de visibilizar que el derecho puede desarrollar un relato de enseñanza y aprendizaje en correspondencia con una de ellas. De ahí que el resultado y la conclusión consiste en que quienes participan de esos procesos pueden asistirse de experiencias humanas mediante un diálogo con historias cinematográficas para comprender las dinámicas del mundo del derecho con el fin de sensibilizar sobre sus estructuras de poder con el ánimo de repensar la vida de los oprimidos y dar respuestas a ellos desde la enseñanza jurídica, entendiendo este proceso como un medio de transformación de la cultura jurídica.

Palabras Clave: epistemología, derecho, enseñanza, cine, oprimidos.

\section{ABSTRACT}

The objective of the article is to reinvent the epistemological dimensions that appear in the teaching and learning of law through the exchange of critical reasons that would be observed with the help of materials such as film histories of cases related to the application of law. For this, the discussion arose from an approach to two types of epistemology: i) that of domination and ii) that of the oppressed, in order to make visible that the law can develop a teaching and learning story in correspondence with one of they. Hence, the result and conclusion is that those who participate in these processes can attend human experiences through a dialogue with film stories to understand the dynamics of the world of law in order to raise awareness of their power structures with the intention of rethinking the life of the oppressed and give answers to them from legal education, understanding this process as a means of transforming the legal culture.

KEYWORDS: epistemology, law, teaching, cinema, oppressed people.

\section{INTRODUCCIÓN}

T a forma de enseñar derecho está afincada en un saber jurídico que reproduce condiciones de acumulación de poder porque transmite el análisis y el estudio de la vigencia de la norma en la sociedad, la cual subyace en un modelo de monismo jurí- 
dico que no permite la convergencia de diferentes epistemes orientados a la comprensión e inclusión de otros paradigmas normativos para su adaptación y convivencia.

Para el presente trabajo se hace referencia a la concepción de los oprimidos desde una doble dimensión: i) como aquellas personas que son víctimas de discriminación, exclusión y abusos de poder, provocadas en gran medida por una teoría del constitucionalismo que es hegemónica y elitista ${ }^{1} \mathrm{y}$, ii) como aquel pueblo latinoamericano que vive en la opresión por fuerzas sociales superiores que corresponden a los grupos opresores y no permiten alcanzar su liberación; así, en todos sus anhelos de cambio, los oprimidos tienen la oposición de quienes tienen el poder, la riqueza y la tierra. ${ }^{2}$

La presente contribución propone una renovación en las metodologías y en los relacionamientos de la enseñanza del derecho a partir de entender que este puede ser la expresión de todos los aportes que pueden generar los oprimidos y los desaventajados que han sufrido quebrantos en sus derechos, lo cual sería posible al pensar un saber jurídico de diálogo e interculturalidad en las diversidades, los pluralismos y el enfoque de género. Así, la fuente principal del derecho sería la adopción de procesos conversacionales con el sentir y el lenguaje de las personas que han sido vulneradas en sus derechos, y no solamente pensar y concebir el derecho desde la fuente de creación de la norma estatal.

La pregunta que ayudó en la formulación del problema fue la siguiente: ¿en qué instante del aprendizaje del derecho, el docente olvida su papel protagónico y se acoge a una voz ajena cuyo contenido se halla fuera de sí mismo por proclamar el discurso excluyente de la norma jurídica vigente? Esa voz ajena, la voz de quien enseña derecho, clausura la voluntad de ser de los oprimidos. Así, la inquietud trasciende a: ¿cómo podrían los sujetos del derecho reencontrar su rol activo y recuperar su mayor apertura para transformar las contradicciones de la epistemología jurídica de la dominación?

La presente investigación analiza la interacción entre los sujetos de aprendizaje del derecho para dimensionar las formas en que el discurso de su enseñanza puede suscitar la reproducción del poder y sus mecanismos de opresión en la sociedad, así como identificar que su estudio puede trascender a dispositivos de emancipación mediante el análisis de la situación de los oprimidos como fuentes transformadoras de la norma jurídica.

1. Ver en la obra de Ramiro Ávila Santamaría, La utopía del oprimido. Los derechos de la naturaleza y el buen vivir en el pensamiento crítico, el derecho y la literatura (Ciudad de México: Akal, 2019), 64 y ss. Revisar el capítulo primero, en la sección sobre el pensamiento crítico y el constitucionalismo del oprimido.

2. Uno de los ejes de la propuesta freireriana consiste en que la pedagogía tradicional para las clases superiores debería cambiarse por una pedagogía para los oprimidos, incorporando una visión crítica del mundo donde viven. Ver Javier Ocampo López, "Paulo Freire y la pedagogía del oprimido", Rhela, vol. 10 (2018): 57-72. 
Para revisar el tipo de epistemología dominante, los criterios metodológicos del texto corresponden a una investigación cualitativa mediante un estudio de observación participante a un número reducido de películas para advertir las limitaciones que se encuentran en los contenidos del derecho como ciencia que edifica un orden hegemónico contra los excluidos.

Para alcanzar ese propósito, utiliza el método cualitativo mediante la técnica de la observación participante para alcanzar un estudio de etnografía judicial mediante la selección de piezas cinematográficas que pueden demostrar la epistemología jurídica de la dominación. Se ha seleccionado un estudio de caso mediante la revisión de producciones cinematográficas para identificar las falencias que puedan presentarse en el derecho como disciplina de estudio.

El trabajo de campo de la presente investigación fue realizado en las obras cinematográficas seleccionadas y que se han obtenido por sus contenidos relacionados a la estética y el derecho.

\section{LA ENSEÑANZA JURÍDICA ES EL APRENDIZAJE DEL CAMPO NORMATIVO DEL PODER}

Las aulas universitarias responden a códigos y rituales simbólicos que moldean las formas de enseñar/aprender a pensar, razonar y argumentar en el pensamiento jurídico. El derecho es un discurso articulado al ejercicio del poder enmarcado en una racionalidad colonial del ser y del saber, en sus propias subjetividades y en sus cuerpos, que conduce a formas siempre recreadas de exclusión, de subalternización y de dominación.

La lógica pedagógica y orientadora en la formación de abogados debe estar planteada precisamente hacia discutir desde miradas integradoras y críticas cómo enseñar y construir un derecho que piense y responda a la vida de los oprimidos.

El camino sería indagar los enfoques subalternos que ofrecen los estudios críticos del derecho para abordar su teoría crítica y asumir las alternativas posibles con el fin de examinarlo como un fenómeno del poder ejercido por aquellos que crean y aplican sus normas. No obstante que una de las razones epistemológicas del derecho es dirigir sus criterios cuestionadores hacia aquellos ámbitos, es indispensable renovar y complementar su locus de enunciación y reconocer las subjetividades y sujetos sociales diversos a quienes esta disciplina jurídica no ha logrado atenderlos para preocuparse por sus vidas y derechos.

Por consiguiente, la formación de quienes estudian para ser abogados debe identificar que la generación del derecho y las formas de acercamiento para su aplicación están constituidas por racionalidades dicotómicas y discriminatorias que configuran 
profundas desigualdades. De modo que hacer a los alumnos partícipes de estas perspectivas de dominación, contribuiría a repensar su rostro opuesto: el derecho como opción de emancipación que altere sus problemáticas.

La visión propositiva que se sugiere exige otro tipo de formación jurídica en los operadores de justicia, abogados y juristas para la construcción de otro paradigma normativo y estatal. El desafío de los estudiantes que quieren ser abogados es cambiar su preparación y mejorar su formación. El desafío de quienes ya lo son es des-aprender lo aprendido para volver a estudiar derecho con otras dimensiones cognitivas y epistémicas, más la inclusión de nuevas sensibilidades y enfoques interculturales e interdisciplinarios. Así, ningún abogado puede sentirse conforme con los sistemas injustos que imperan en las realidades latinoamericanas.

La propuesta de esta sección está pensada para revisar críticamente la formación y cultura jurídica de abogados, operadores de justicia y juristas con la disposición de mirarlos como gestores de un cambio social. Para el efecto, se examinan y proponen los saberes, actores, contextos y modelos para formular nuevos procesos de enseñanza/aprendizaje, donde el derecho pueda ser asumido como un instrumento y una oportunidad que permita estudiar e intervenir en las sociedades hacia sus innovaciones y cauces más igualitarios.

Ahora bien, para aproximarnos a explicar la naturaleza del derecho, lo haremos a partir de analizar brevemente una parte mínima del pensamiento de Pierre Bourdieu. ${ }^{3}$ Uno de los aportes de su teoría consiste en identificar varias categorías analíticas como la formación del campo jurídico que sería también uno de los componentes que define el derecho realmente aplicable; y, así, explica que en este contexto los profanos -o usuarios de la justicia- son quienes dependen y son afectados por ese campo, considerando que, pese a ser los potenciales beneficiarios de los servicios y los derechos en torno a la justicia, no son parte de las decisiones del sistema, ni participan de ellas para responder a sus necesidades. Si el campo jurídico es la expresión de intereses de actores por decidir el derecho y por ejercer el poder de su monopolio, una visión emancipadora del saber jurídico puede intentar dar señales para desafiar ese sistema. Sentado ello, la formación en esta disciplina puede promover una ruptura fundacional: ser concebida para cambiar la realidad y alterar las lógicas discriminatorias y excluyentes del poder. No podemos seguir enseñando y aprendiendo para agudizarlas.

Luego, uno de los enfoques empleados por Bourdieu es el correspondiente a la división del trabajo jurídico, para lo cual se basa en la historia del derecho social

3. Pierre Bourdieu, "La fuerza del derecho: hacia una sociología del campo jurídico", en Pierre Bourdieu y Gunther Teubner, La fuerza del derecho (Bogotá: Ediciones Uniandes, 2000), 155-220. 
y asegura que la disciplina jurídica registra siempre un estado de relación de fuerzas y ratifica así las conquistas de los dominadores. Según este autor, al interior del campo jurídico existe una división del trabajo que se determina por la rivalidad estructuralmente reglada entre los agentes y las instituciones que operan en esta esfera. Ciertamente, uno de los problemas se presenta porque el mundo del derecho estaría condicionado por la interpretación de normas legales y que, si bien la ley ya es una expresión de luchas de distinto tipo, al momento de interpretarlas, el operador recoge y se apropia de esa fuerza simbólica encerrada en ese espacio.

Y señala oportunamente que, como en otros ámbitos de poder, el campo jurídico funciona como un aparato donde la justicia "organiza no solo las instancias judiciales y sus poderes según una estricta jerarquía y por tanto también las decisiones y las interpretaciones que se autorizan mediante ellas, sino también las normas y las fuentes que otorgan autoridad a esas decisiones". ${ }^{4}$

En el pensamiento de Bourdieu, el producto de la división del trabajo sería la elaboración de un cuerpo de reglas y de procedimientos con pretensión universal, pero este producto se desarrolla a partir de la rivalidad entre diferentes formas de competencia profesional -antagonistas y complementarias- que funcionan como capital específico. Asimismo, anota algo importante: "la significación práctica de la ley no se determina realmente sino dentro de la confrontación entre los diferentes cuerpos (magistrados, abogados, notarios, etc.) animados por intereses específicos divergentes". Por consiguiente, la producción y el discurso jurídico se hacen en una lucha simbólica de distintas posiciones. Para este autor, la forma del cuerpo jurídico -en cuanto a su grado de formalización y normalización-depende de la fuerza relativa de los teóricos y de los prácticos, de profesores y de jueces, de exégetas y de expertos, dentro de las relaciones de fuerza características de un estado del campo.

Por otra parte, uno de los ejes de su pensamiento se refiere al establecimiento del monopolio, y lo explica indicando que recurrir al derecho supone el reconocimiento de una definición de las formas de reivindicación o de lucha que privilegia las luchas individuales (y legales) en detrimento de otras formas de lucha. La instauración del monopolio de los profesionales sobre la producción y la comercialización de esta categoría de productos, que son los servicios, es lo que también constituye al campo jurídico. Este autor enseñaría que los problemas jurídicos son creados por los propios profesionales para crear sus servicios y, en ese contexto, se presenta la siguiente realidad:

El descubrimiento de la injusticia como tal reposa en el sentimiento de tener derechos (entitlement), y el poder específico de los profesionales consiste en la capacidad de revelar

4. Ibíd., 163. 
los derechos y al mismo tiempo las injusticias o, al contrario, de censurar el sentimiento de injusticia fundado sobre el solo sentido de la equidad y, por ese medio, disuadir la defensa judicial de derechos subjetivos. Los profesionales tienen, en definitiva, el poder de manipular las aspiraciones jurídicas, de crearlas en ciertos casos, de amplificarlas o de disuadirlas en otros. ${ }^{5}$

Otro de los nudos problemáticos que presenta su teoría es el poder de nombrar y consiste en que para constatar qué es el derecho, en sus contenidos y efectos, es imprescindible comprender la lógica del trabajo jurídico en cuanto a su formalización, y evidenciar que existen intereses sociales de los agentes formalizadores que se ubican al interior del campo jurídico y en la relación entre este y el campo del poder en su conjunto. En ese contexto, las prácticas de los agentes encargados de producir el derecho o de aplicarlo depende de las afinidades que unen a los detentadores de la forma por excelencia del poder simbólico con los detentadores del poder temporal, político o económico, y esto a pesar de los conflictos de competencia que puede enfrentarlos.

Para concluir este fugaz abordaje, sin que ello signifique agotar la teoría bourdieuniana para interpretar la complejidad del derecho, ${ }^{6}$ haré alusión a los efectos de la homología, la cual es explicada desde la siguiente relación: a medida que se incrementa la fuerza de los dominados en el campo social y la de sus representantes en el campo político, la diferencia del campo jurídico tiende a incrementarse. El autor resalta el siguiente fenómeno:

La función de mantenimiento del orden simbólico que el campo jurídico contribuye a asegurar es -al igual que la función de reproducción del propio campo jurídico, sus divisiones y sus jerarquías, y del principio de visión y de división que es su fundamento- el producto de incontables acciones que no tienen por fin el cumplimiento de esa función y que pueden incluso inspirarse en intervenciones opuestas, como los proyectos subversivos de las vanguardias que contribuyen, en definitiva, a determinar la adaptación del derecho y del

5. Ibíd., 190.

6. Quisiera exponer un esquema rápido de actores y procesos que intervendrían en el campo jurídico según la teoría de Bourdieu y que lo adapto para explicarlo con relación al ejercicio de derechos. Con respecto a la categoría de campo, este contribuye a explicar cuando los sujetos señalan dificultades y acciones de exclusión que no permiten un ejercicio de derechos sin conflictos; en relación al campo específico, según la naturaleza de los campos, las tensiones pueden ser más agudas para ejercer sus derechos; sobre el hábitus, cuando se quiere analizar la implementación de políticas públicas conforme la normativa legal que promueve ciertos derechos, es dable aproximarse a los sujetos de derechos que encuentran dificultades impuestas por las reglas en un escenario concreto; en cuanto a la categoría de subversión, contribuye a revisar las dimensiones internas y externas de un hecho con el agregado de repasar los cambios que formulan los sujetos y, finalmente, la categoría de la división del trabajo ayuda e explicar por qué los sujetos no se sienten con condiciones para ejercer sus derechos y las responsabilidades de la institucionalidad en cuanto a los objetivos constitucionales. Ibíd., 160 y ss. 
campo jurídico al nuevo estado de relaciones sociales y a asegurar así la legitimación de la forma establecida de estas relaciones. ${ }^{7}$

Como se puede apreciar, el derecho tiene múltiples implicaciones y vínculos de poder que condicionan su control y expansión para su real funcionamiento. Veamos ahora cómo el saber jurídico y sus discursos están estructurados por una epistemología de la dominación.

\section{LA EPISTEMOLOGÍA JURÍDICA DE LA DOMINACIÓN}

Para describir la epistemología de la dominación en los saberes jurídicos, se utilizará una perspectiva interdisciplinaria de la sociología y la lingüística con los aportes teóricos de Boaventura de Sousa Santos y Michel Foucault para la interpretación del tema en análisis.

El saber jurídico tiene una directa relación con las estructuras de poder y opera para custodiarlas. Al hacer una analogía de la teoría de la epistemología de la ceguera de Boaventura de Sousa Santos, se puede afirmar que el conocimiento jurídico de los ejecutores del derecho (en adelante, entiéndase a los abogados, docentes y operadores de justicia) contiene estructuras imaginativas y límites de representación que contraría las condiciones de emancipación para la protección y remediación de los derechos.

Ese conocimiento opera en la representación distorsionada de las consecuencias y manifiesta una tensión entre las experiencias y las expectativas. La distorsión operaría por la creación sistemática de ilusiones de correspondencia con lo que se pretende analizar los tipos de violación de los derechos, sus causas y sus consecuencias. Así, los ejecutores del derecho no detectarían fenómenos de los actos u omisiones que violan los derechos o los ámbitos de opresión en los que actúa la disciplina jurídica, sino las escalas de los fenómenos.

En el estudio de la ciencia normativa es importante considerar que los ejecutores del derecho no asumen la determinación de la relevancia al momento de dar respuesta a los eventuales campos de dominación, por cuanto, como diría de Sousa Santos, "la relación de un objeto dado de análisis no reside en el objeto en sí, sino en los objetivos del análisis. Objetivos diferentes producen diferentes criterios de relevancia". ${ }^{8}$

7. Ibíd., 219-20.

8. Boaventura de Sousa Santos, Una epistemología del sur (Ciudad de México: CLACSO / Siglo XXI, 2009), 66. 
Desde luego, un fenómeno específico solo puede ser representado en una escala específica y la dificultad reside en que las diferencias de escala pueden ser cuantitativas y cualitativas a la hora de revisar las maneras y los efectos en que interviene la epistemología jurídica de la dominación. Este autor afirma que, según el tipo de mediación que se haga, se puede distorsionar la realidad y caer en imprecisiones, dependiendo del mapa que pueda emplearse, y sostiene que:

Cada escala representa un fenómeno y distorsiona o esconde otros. Muchos de los debates en las ciencias sociales resultan de la sobreposición de los fenómenos creados y analizados en diferentes escalas. La escala es un 'olvido coherente' que tiene que ser llevado a cabo coherentemente. Como mediación entre la intención y la acción, la escala se aplica también a la acción social. [...] El poder representa la realidad física y social en una escala elegida por su capacidad de crear fenómenos que maximicen las condiciones de reproducción del poder. La distorsión y la ocultación de las realidades es, por eso, un presupuesto del ejercicio del poder. ${ }^{9}$

Existe una explicación de los saberes desde la episteme de cada individuo, la cual expresaría el dominio del saber y cómo este representa la visión teórica y práctica para la conformación del discurso. Esta teoría desarrollada por Michel Foucault, también la ubica desde la relación entre saber e ideología y cómo el primero se convierte en práctica porque acoge un sistema de formación de sus objetos, de sus tipos de enunciaciones, de sus conceptos y de sus elecciones teóricas. ${ }^{10}$

En lugar de recorrer el eje conciencia-conocimiento-ciencia (que no puede ser liberado del índice de la subjetividad), la arqueología recorre el eje práctica discursiva-saber-ciencia. Y mientras la historia de las ideas encuentra el punto de equilibrio de su análisis en el elemento del conocimiento (hallándose así obligada, aun en contra suya, a dar con la interrogación trascendental), la arqueología encuentra el punto de equilibrio de su análisis en el saber, es decir en un dominio en que el sujeto está necesariamente situado y es dependiente, sin que pueda figurar en él jamás como titular (ya sea como actividad trascendental, o como conciencia empírica). ${ }^{11}$

Foucault pensó en la arqueología del saber para entender las condiciones del saber y su epistemología como posibilidades históricas. Así, la práctica discursiva ha creado un estado de positividad que perfora y moldea los saberes.

9. Ibíd., 67.

10. Michel Foucault, La arqueología del saber (Buenos Aires: Siglo XXI, 1979), 304-7.

11. Ibíd., 307. 
El saber jurídico es un discurso que recrea y transmite colonialidad y que se alimenta de discursos y prácticas volátiles que utilizan ciertos mecanismos para prefigurar la realidad: escala, proyección y simbolización. Estas categorías, empleadas por B. De Sousa Santos, permitirían explicar las dificultades existentes según la determinación que se emplee para encontrar las preguntas o respuestas presentes en el derecho: una respuesta de regulación o una respuesta de emancipación frente a las situaciones que viven los oprimidos.

Los ejecutores del derecho tienen dos alternativas para su estudio: i) adoptar alternativas integrales para la búsqueda de soluciones dialógicas que involucren un proceso conversacional con las angustias que viven los oprimidos o ii) negar su intervención en ese tipo de escenarios por alegar que la resolución de sus problemas únicamente se la puede encontrar en las normas vigentes.

Aquella disquisición está situada en el centro de los saberes jurídicos que distinguen al momento de enseñar el derecho porque pueden indagar la construcción de posibilidades que se presenten como una crítica a la homogeneidad científica de esta disciplina -entiéndase así a la referencia del derecho como ciencia dominante-. Por ello, este debate supone revisar las epistemes que sustentan el conocimiento que tenemos de ella al momento de analizarla, en tanto que puede estar impedida de propiciar rupturas paradigmáticas al momento de ofrecernos una visión de cómo es la sociedad.

Por ello, la cuestión para el análisis reside en cuestionar cuál es la metodología que emplean los ejecutores del derecho cuando lo estudian y lo interpretan. Una tendencia recurrente de ellos consiste en interpretar la realidad y los problemas iusfundamentales hasta donde la norma permite su resolución; sin embargo, ello significaría reproducir las perspectivas individuales de quienes deciden, sin dejar que las personas directamente involucradas en sus derechos puedan ser parte de la decisión judicial. Entonces, pensar la epistemología de la dominación supone indagar por qué tiene el derecho tantas dificultades para reconocerse en otras fuentes de discusión y participación desde los pluralismos y las diversidades, en lugar de que sea solamente el monismo jurídico el principal y casi único modelo normativo de generación y punto de decisión de las diferencias existentes en la sociedad.

Las metodologías de análisis del derecho utilizan conceptos y categorías donde la norma habla, siente y soluciona en nombre de los otros, sin permitirles directamente mediar y ser parte del ordenamiento jurídico válido, y los sitúa como meros receptores de una determinación final. Así, la epistemología de la dominación funcionaliza los medios para una continua producción de comprensiones en repertorios excluyentes, donde se apodera y anula los elementos materiales que permitirían la búsqueda de alternativas dialógicas con los oprimidos y crea un ordenamiento hermético y cerrado a las formas dialógicas con la ciudadanía. 
El razonamiento normativo ignora una epistemología inclusiva: toda acción humana, en pleno uso de sus derechos y garantías, se produce y se explica a partir de la relación específica de cómo los individuos que intervienen en ella responden a una particular situación que supone un tipo de protección o reparación diferenciada. La palabra de la norma lo invade todo porque lo necesita todo, expandiendo un razonamiento que empieza y se agota en su plexo discursivo al momento de adoptar la última palabra. La epistemología jurídica detenta un conocimiento conocido que considera tener todos los medios adecuados para entender y concebir una forma de comprender los problemas en torno a los derechos y, de esa forma, anula gradualmente las posibilidades de un pleno uso de la conciencia universal para entender las dimensiones concretas de cada situación donde viven y sufren los marginados.

\section{ENFRENTAR LA COLONIALIDAD DE LA CIENCIA JURÍDICA PARA REHACER EL DERECHO DESDE LAS VOCES DE LOS DESAVENTAJADOS Y SU REALIDAD: EL CINE COMO CAMINO PEDAGÓGICO}

El estudio y la enseñanza del derecho requiere de una epistemología distinta para escuchar a los afectados, no para interpretarlos, sino para rehacer el derecho desde su realidad. La racionalidad colonial del derecho tiene como finalidad moldear y domesticar el sentir de las víctimas, cuando son ellas las que impugnan la colonialidad del saber, del ser y del sentir del derecho por no darles el lugar que necesitan en su dolencia para alcanzar sus derechos.

Los marginados son ignorados por la norma en sus problemas concretos. Mientras la epistemología jurídica de la dominación se activa para que sean olvidados, proponer la descolonización del derecho es recordarle su existencia para que habite en su dolor para mirar en esas personas otro ordenamiento jurídico.

La enseñanza del derecho para construir una epistemología de los oprimidos supone visualizar el proyecto de poder que instaura el derecho positivo y poner en evidencia la existencia de pluralismos y diversidades como una alternativa de enunciación que ofrece espacios materiales, vitales y simbólicos que pueden contrarrestar la epistemología de la dominación. Se trata, por cierto, de una propuesta descolonizadora para discutir a la hegemonía de la enunciación del poder y su discurso: un relato del nombrar de los dominadores para hablar que excluye las voces de los excluidos.

La positivización del derecho puede ser discutida desde sus imposibilidades para dar la voz directa y sostenida a los oprimidos en sus derechos y asumir la enseñanza para indagar en esas realidades y explorar las limitaciones de la ciencia jurídica cuando pretende asumirse exclusivamente como un conocimiento técnico para crear 
hegemonía en su epistemología y blindar las puertas de apertura a toda forma de afectividad que pueda cuestionar el disciplinamiento del poder jurídico y sus instituciones.

Ahora bien, ¿cómo rehacer la epistemología para deconstruirla e insertar los conocimientos, saberes y sabidurías de los sectores que expresan experiencias de vida que el derecho no ha logrado dar respuestas efectivas a sus sentidos de existencia? El cine puede ofrecer elementos programáticos y pragmáticos para ello. A continuación, se hará una descripción de películas y una aplicación de los conceptos referidos en el análisis respectivo que se mencionará con las iniciales A. C.

En la película En el nombre del padre ${ }^{12}$ se puede apreciar las injusticias del derecho penal e identificar la degradación de los derechos cuando una persona inocente ha sido condenada y su defensa le puede costar hasta su propia vida para no doblegar ante el poder supremo del derecho contra los oprimidos en las prisiones.

A. C.: En esta representación pueden extraerse varios prolegómenos relacionados al sistema de rehabilitación social: i) la corrupción de la administración de justicia penal compuesta por jueces flexibles a las influencias de todo tipo, agentes policiales manipulados/manipuladores y abogados funcionales al statu quo, ii) la condena a una persona inocente, a quien la institucionalidad judicial le demuestra que no debió ser juzgada cuando ya es tarde porque ha muerto, iii) la falta de alternativas y medios de rehabilitación para las personas privadas de la libertad y el consumo de drogas como único camino al que sucumben, iv) la ausencia de políticas de salud y cuidado para las personas privadas de la libertad, a pesar de portar enfermedades mortales y a quienes sus condenas pueden ser equivalentes a una pena de muerte, v) el complot de la institución policial para perseguir a personas inocentes, fraguar pruebas, impulsar investigaciones direccionadas y el poder de altos mandos policiales para esconder la verdad de los hechos investigados y evitar el descrédito que generaría para la institucionalidad.

La proyección de la realidad de los oprimidos puede concebirse desde la vida de la población que habita en los centros de rehabilitación: son los más pobres de entre los pobres y las perspectivas de que su situación cambie es prácticamente nula porque para la administración jurisdiccional, el Estado y la sociedad, ellos no existen y, si acaso existen, son a quienes debe imponerse todo tipo de tratos crueles.

En la película Matar a un ruiseñor, ${ }^{13}$ se contempla cómo un ordenamiento jurídico puede consagrar y legitimar las variadas formas de la discriminación y racismo contra un grupo social.

12. Jim Sheridan, En el nombre del padre (Irlanda / Reino Unido: Hell's kitchen films), 1993, DVD.

13. Robert Mulligan, Matar a un ruiseñor (Estados Unidos: Universal Pictures), 1962, DVD. 
A. C.: En esta pieza cinematográfica se evidencia la problemática de la exclusión a quienes pueden ser equivalentes a otros grupos de poblaciones de oprimidos: los débiles de una sociedad. Uno de los aportes es apreciar cómo desde la formación de la niñez se transmiten imaginarios discriminatorios que se naturalizan para reproducirlos posteriormente. Así, los recuerdos y vivencias se contagian de episodios violentos que demuestran también la vigencia de estructuras de desigualdad social, con conflictos raciales donde el odio determina la condición de acceso o restricción a los derechos.

Por otra parte, es posible inferir la necesidad de que los abogados asuman la defensa de aquellas causas que implican consecuencias de distinta índole porque suponen enfrentamientos con poderes hegemónicos que buscan preservar un orden dominante. Por tanto, la relación con el tema en cuestión radica en que los oprimidos requieren que los abogados impulsen la defensa jurídica de sus casos, aunque ello pueda afectar la vida de los patrocinadores y su entorno.

El film Un hombre para la eternidad ${ }^{14}$ puede visualizar el poder omnipresente de las autoridades políticas y cómo el derecho puede crear las condiciones institucionales y democráticas para favorecer ese poder omnímodo.

A. C.: Esta pieza es relevante para el estudio de los oprimidos porque puede mostrarnos que en los ámbitos políticos, religiosos o de otro tipo, existen principios que ayudan a descifrar las respuestas que debe dar el derecho. Al mismo tiempo, contribuye a mirar que las decisiones que entrañan diferencias jurídicas pueden ser resueltas desde la perspectiva de normas morales que inciden en la resolución final.

En uno de los diálogos de la representación se escucha el siguiente diálogo de uno de los protagonistas: "cuando los hombres de estado se olvidan de su propia conciencia y colocan en segundo lugar sus deberes públicos, conducen a su patria por el camino más corto hacia el caos". ${ }^{15}$ Las autoridades de un Estado pueden adoptar políticas que respondan a sus obligaciones de proteger los derechos humanos y a los grupos desventajados, pero, si es que lo hacen desvinculándose de estos ámbitos, lo más seguro es que los más perjudicados pueden ser los grupos más vulnerables de la población.

La película El proceso ${ }^{16}$ describe una situación de vulneración de una persona que se encuentra imputada en una investigación y no se le reconocen las garantías procesales mínimas para el ejercicio de sus derechos humanos.

14. Fred Zinneman, Un hombre para la eternidad (Reino Unido: Highland films), 1966, DVD.

15. Ibíd.

16. Orson Welles, El proceso (Francia/Alemania/Italia: Paris Europa Productions), 1962, DVD. 
A. C.: Esta pieza artística está basada en una de las obras literarias más leídas para el mundo jurídico: El proceso de Franz Kafka. ${ }^{17}$ Es común conocer en el ámbito jurídico sobre procesos investigativos en cualquier materia donde existen serias fisuras a las garantías del debido proceso: la persona investigada no conoce las razones por las que le investigan; se inician procesos de juzgamiento sin la motivación legal para hacerlo; la persona imputada es sancionada injustamente, la burocracia judicial interviene en contra de la persona y lo hace a favor del interés que le conviene al poder -en cualquiera de sus formas-. Probablemente, la metáfora que más se ajusta a la sensación de inseguridad e incertidumbre es la figura de Gregorio Samsa transformado en una cucaracha que clama por un poco de consuelo de su familia.

La presencia de juicios corruptos podemos encontrar desde la época de Sócrates cuando se enfrenta a los sofistas y, la constatación, desde allí hasta ahora, es que el sistema judicial puede condenar injustamente por una premisa central: "cuando el poder quiere acusar a alguien, lo van a conseguir, incluso legalmente. [...] El juicio de Sócrates es una prueba de cómo se podía encarcelar o matar a alguien, de modo legal, más allá de las pruebas concretas reales que existían para que la justicia estableciera su veredicto". ${ }^{18}$

El film Philadelfia ${ }^{19}$ representa las situaciones de discriminación que debe afrontar una persona portadora de VIH para sobrevivir y trata también los escenarios de violencia y exclusión que existen contra las diversidades sexuales en una sociedad.

A. C.: Para replicar esa representación en un análisis de la epistemología del oprimido, puede advertirse que existen distintos colectivos sociales que sufren variadas situaciones de discriminación y, frente a ello, el derecho debe velar por ellos y dar respuestas múltiples: desde el activismo social y judicial, la vigencia de garantías jurisdiccionales y constitucionales, el desarrollo de políticas públicas, la constitucionalización del ordenamiento jurídico, entre otras. Se trata, entonces, de innovar los problemas de exclusión hacia un desarrollo profundo de los derechos para los grupos discriminados.

Los oprimidos también son aquellos individuos que reciben el trato abusivo de la administración de justicia cuando no es capaz de tutelar sus garantías al debido proceso y no pueden encontrar las respuestas de remediación, restitución o reparación a sus derechos afectados en los órganos administrativos o judiciales que le juzgaron sin cuidar su derecho elemental a la tutela judicial efectiva.

17. Franz Kafka, El proceso (Madrid: Valdemar, 2016).

18. Darío Sztajnszrajber, Filosofia a martillazos, t. I. (Buenos Aires: Paidós, 2019), 203-4.

19. Jonathan Demme, Philadelfia (Estados Unidos: Tri Star Producciones), 1993, DVD. 
La película El abogado del diablo ${ }^{20}$ recrea las disyuntivas y ambivalencias que enfrenta el abogado en el ejercicio de su profesión y escenifica los intersticios en los que actúa, a los cuales no llega el ordenamiento jurídico para regularlos.

A. C.: El desempeño de los abogados puede ser motivo de estudio cuando se pretenda responder a esta pregunta: ¿existen códigos informales que establecen las conductas permitidas y no permitidas en el ejercicio jurídico profesional? La cultura y las prácticas de los abogados crean un campo jurídico, donde solo entienden sus significados quienes son parte de aquel porque conviven y entienden el habitus y las intersubjetividades que lo regulan. Para la situación de los oprimidos, es oportuno estudiar cómo actúan los abogados porque pueden ser formados con valores orientados a la búsqueda de la justicia y la preocupación por lo que afrontan los grupos desaventajados de la población.

El film El inocente $^{21}$ se encarga de develar las restricciones de la política criminológica de un Estado y las realidades de marginalidad de una sociedad, donde el derecho penal las agudiza y recrudece los niveles de exclusión.

A. C.: Los cuestionamientos perfilados a identificar cuándo una norma jurídica es justa o injusta no pueden desvincularse de los estudios sistémicos al derecho constitucional, derecho penal y, otros, para dimensionar los fenómenos de preservación y acumulación de poder que se puede gestar desde el derecho para suscitar niveles de disciplinamiento de la comunidad por medio del control social desde el Estado a los individuos.

Un ordenamiento jurídico también puede contener formulaciones discriminatorias o violentas que no se corresponden con los fines sociales que anuncia garantizar. En los contenidos de ese ordenamiento puede evidenciarse la conformación de estructuras de poder destinadas a consagrar un poder dominante por sobre grupos que reciben formas de opresión desde el Estado: las personas en situación de libre movilidad internacional, los gestores y practicantes de culturas urbanas, las personas con sentencia condenatoria como consecuencia de actos de tráfico de influencias en los operadores de justicia, los activistas sociales que se declaran en resistencia y reciben formas de criminalización del aparato estatal, entre otros.

La película $E l$ veredicto ${ }^{22}$ ubica las dimensiones de las decisiones judiciales y la responsabilidad de los operadores de justicia de cara a los problemas más sensibles para los derechos.

20. Taylor Hackford, El abogado del diablo (Estados Unidos: Regency enterprises), 1997, DVD.

21. Brad Furman, El inocente (Estados Unidos: Lionsgate), 2012, DVD.

22. Sidney Lumet, El veredicto (Estados Unidos: 20th century fox), 1982, DVD. 
A. C.: Las decisiones de los operadores de justicia no solamente responden a criterios técnicos y a la aplicación de la norma. También pueden responder a disputas de poder de grupos políticos o económicos que inciden en esos operadores. Sin embargo, existen personas que asumen la responsabilidad de esas decisiones y ellos deben dirimir cómo resuelven un determinado problema y cómo lo dejan a la sociedad en relación a las disputas de poder que se presentaron. Más allá de todo ello, están las personas que sufren o sufrirán a partir de esas decisiones y lo que debe señalar el estudio del derecho como preocupación es: cómo queda la vida de las oprimidos después de las decisiones judiciales, ¿sigue siendo la misma, a pesar de que otros se beneficiarán a costa de los desaventajados?

Obsérvese que el cine es un recurso para transparentar los recovecos opacos del derecho y desentrañar sus caminos plagados de trampas, en donde los más débiles tienen las mayores tendencias a perder sus derechos y su dignidad. Así, el universo normativo puede concebirse como una imposición, una irrupción, como un poder no legitimado. Por tanto, las decisiones que se derivan de ese universo quedan confinadas a un poder artificial de intereses y cálculos caracterizados por la opacidad frente a la discusión pública. Las películas citadas ayudan a vislumbrar cómo se despliega la epistemología de la dominación y cómo los ejecutores del derecho son funcionales a ella para poner trabas a la consecución de los derechos de las personas justiciables.

Construir un paradigma de recomposición de la epistemología es pensar el derecho como un registro de memoria y de identidad sobre al abatimiento de las personas que sufrieron sus derechos para procurar la conexión de los saberes de aquellos actores olvidados y cuyas experiencias son consideradas como un desperdicio por la epistemología hegemónica de la ciencia jurídica.

La inquietud gravitante gira alrededor de cómo articular entre sí los saberes de los marginados para que tengan un lugar en el estudio del derecho aquello situaría la discusión desde cuestionar la vigencia de un paradigma jurídico hegemónico, que se niega a admitir su crisis y disfunciones en su estructura lógico-formal de múltiples formas institucionalizadas y, lo hace precisamente para no perder su hegemonía. Como afirma Wolkmer:

El proyecto jurídico positivista, descartando los análisis de dominio de la práctica política y de las relaciones sociales, se encerró en posiciones meramente descriptivo-abstractas y en metodologías lógicas basadas en procedimientos lógico-lingüísticos. Eso significa que, por más que la dogmática jurídica estatal se revele, teóricamente, resguardada por la aureola de su base científica, su competencia, solidez y seguridad, sin embargo en la práctica se intensifica la gradual pérdida de su funcionalidad y de su eficacia. Por esa razón se presenta la inevitable crisis de ese modelo de legalidad. Por así decirlo, la crisis del 
monismo jurídico estatal viene reflejando el constante '[...] divorcio entre las estructuras socio-económicas y las instituciones jurídico-políticas’. ${ }^{23}$

Wolkmer explica que la formalización de la dogmática jurídica, como resultado de datos lógicos y padrones de control jerarquizados inmunes a proposiciones y a juicios axiológicos, reduce el derecho al orden vigente. Por ello, "la instrumentación del derecho en cuanto técnica coactiva marcada por la sanción organizada, reposa en la autoridad estatal y en los mecanismos formales que diluyen los influjos condicionantes de las formas ideológicas". ${ }^{24}$

Si se asume que la validez y eficacia del ordenamiento jurídico se basaría en la positividad creada y sustentada por el Estado, es preciso preguntar: ¿pueden los ejecutores del derecho deconstruir los cimientos de la estatalidad, la unidad, la positividad y la racionalidad que devienen en un monismo jurídico que sustenta las definiciones de esta disciplina jurídica?

\section{CONCLUSIONES}

El cine puede subvertir los cánones sagrados de la enseñanza/aprendizaje del derecho para sugerir las variaciones que trastoquen su epistemología de la dominación. Los relatos cinematográficos contribuyen en la enseñanza jurídica porque coadyuvan a un diálogo intercultural y humano con cada realidad donde se pretende aplicar la norma jurídica.

Los discursos que encontramos en las películas y las interacciones de sus protagonistas en el mundo jurídico permiten identificar metáforas y representaciones que están presentes en el universo del derecho y que, en un estudio exclusivo de las instituciones y textos normativos, no permitirían vislumbrarlo de forma directa.

El derecho es capaz de conservar la epistemología de la dominación o puede promover realidades de desarrollo a los derechos y sus garantías en una perspectiva de protección a los oprimidos. En ese contexto, la utilización de piezas cinematográficas ayuda a desentrañar cuáles son las opciones que puede presentar un sistema jurídico y las adversidades que se derivan de él.

La relación de la formación universitaria en derecho con el cine pretende ensayar una epistemología de los oprimidos, a partir de promover un engranaje de las voces de

23. Antonio Carlos Wolkmer, Pluralismo jurídico. Fundamentos de una nueva cultura del derecho (Sevilla: MAD, 2006), 66.

24. Ibíd., 69. 
los marginados con los sujetos ejecutores del derecho en la perspectiva de crear una racionalidad de intercambio de saberes para un desarrollo argumentativo que ponga de manifiesto la interacción para la búsqueda de los acuerdos epistemológicos, en donde se supere la rigidez jerárquica para acercar los modos de vida de las personas marginadas y descartadas por la epistemología jurídica de la dominación, donde aquellas no se vean sometidas estrechamente a una visión de la estatalidad, la organización burocrática y el formalismo legal, sino que al estudiarlas les otorguemos una voz para escucharlos y fomentar una racionalidad material, donde los procedimientos técnico-formales no se conviertan en barreras que establecen que aquellos engranajes se superpongan.

Deconstruir las metodologías para la enseñanza y aprendizaje del derecho supone adoptar como recursos prácticos a obras cinematográficas que pueden mostrar que en un sistema jurídico subsisten valores, discursos e identidades que encuentran correspondencia con una epistemología de la dominación, ante lo cual su estudio facilita las comprensiones hacia la necesidad de una epistemología de los oprimidos para acercar el derecho a los sentidos y a lo cotidiano mediante la contemplación de cómo se aplica el derecho en las tramas cinematográficas desde las pasiones, las emociones y los argumentos que subyacen en cada situación jurídica.

\section{BIBLIOGRAFÍA}

Ávila Santamaría, Ramiro. La utopía del oprimido. Los derechos de la naturaleza y el buen vivir en el pensamiento crítico, el derecho y la literatura. Ciudad de México: Akal, 2019.

Bourdieu, Pierre. "La fuerza del derecho: hacia una sociología del campo jurídico". En Pierre Bourdieu y Gunther Teubner, La fuerza del derecho. Bogotá: Ediciones Uniandes, 2000.

Córdova Vinueza, Paúl. Derechos sin poder popular. Quito: Centro Andino de Estudios Estratégicos / Centro de Estudios Construyendo Ciudadanía y Democracia de la Universidad Central del Ecuador, 2013.

- "Propuesta sobre la enseñanza del derecho constitucional. Hacia una teoría de sus estudios jurídicos críticos". Indisciplinas. Vol. 2, n. ${ }^{\circ} 4$ (2016).

Córdova Vinueza, Paúl, Lorena Cueva y María Paula Romo. "Debates y desafíos en la enseñanza del derecho en Ecuador". Cuadernos del Contrato Social por la Educación-Ecuador 10 (2014).

De Sousa Santos, Boaventura. Una epistemología del sur. Ciudad de México: CLACSO / Siglo XXI, 2009.

Foucault, Michel. La arqueología del saber. Buenos Aires: Siglo XXI, 1979.

Guerrero Arias, Patricio. Corazonar. Una antropología comprometida con la vida. Quito: Abya-Yala / Universidad Politécnica Salesiana, 2010.

Kafka, Franz. El proceso. Madrid: Valdemar, 2016. 
Ocampo López, Javier. "Paulo Freire y la pedagogía del oprimido". Rhela. Vol. 10 (2018): 57-72.

Sztajnszrajber, Darío. Filosofía a martillazos. T. I. Buenos Aires: Paidós, 2019.

Thury Cornejo, Valentín. “El cine, ¿nos aporta algo diferente para la enseñanza del derecho?”. Academia. Revista sobre enseñanza del derecho, año 7, n. ${ }^{\circ} 14$ (2009): 59-81.

Universia. "12 películas imprescindibles para estudiantes de derecho”, 12/09/17. Madrid, España. Disponible en: 〈http://noticias.universia.es/consejos-profesionales/noticia/2015/10/28/ 1132935/12-peliculas-imprescindibles-estudiantes-derecho.html〉. Consulta: 20 de marzo de 2018.

Wolkmer, Antonio Carlos. Pluralismo jurídico. Fundamentos de una nueva cultura del Derecho. Sevilla: MAD, 2006.

\section{Películas}

Demme, Jonathan. Philadelfia. Estados Unidos: Tri Star Producciones, 1993. DVD.

Furman, Brad. El inocente. Estados Unidos: Lionsgate, 2012. DVD.

Hackford, Taylor. El abogado del diablo. Estados Unidos: Regency enterprises, 1997. DVD.

Lumet, Sidney. El veredicto. Estados Unidos: 20th century fox, 1982. DVD.

Mulligan, Robert. Matar a un ruiseñor. Estados Unidos: Universal Pictures, 1962. DVD.

Sheridan, Jim. En el nombre del padre. Irlanda / Reino Unido: Hell's kitchen films, 1993. DVD.

Welles, Orson. El proceso. Francia /Alemania / Italia: Paris Europa Productions, 1962. DVD.

Zinneman, Fred. Un hombre para la eternidad. Reino Unido: Highland films, 1966. DVD. 